\title{
tribal warfare and transformative justice in the new guinea highlands
}

\author{
Alan Rumsey \\ Department of Anthropology \\ Research School of Pacific and Asian Studies \\ Australian National University
}

\section{Introduction}

In his recent wide-ranging review of the theory and practice of restorative justice, John Braithwaite proposes that all cultures have traditions of restorative and retributive justice and, that 'in the circumstances of the modern world, they will find their restorative traditions a more useful resource than their retributive traditions'. ${ }^{1}$ In this chapter I am going to be weighing up these assertions about 'all cultures' against evidence from one particular culture area where I have been doing anthropological fieldwork over the past twenty years, the Western Highlands of Papua New Guinea. This is a region with a justified reputation for recurrent rounds of tribal warfare. But although less well known, it is also a region with its own ways of making peace, some of them long-established and others recent and remarkably innovatory. These practices are of a kind with which advocates of restorative justice can readily identify (as evident from the discussion at the Port Vila conference from which this volume has arisen). But I am going to argue that, in order to comprehend them in those terms, the theory of restorative justice needs to be refined. For these practices among Highlanders, and some of the 
most basic cultural assumptions behind them, are inconsistent with the ways in which western advocates of restorative justice usually think about it in relation to retributive justice.

To see how, let us begin with what Braithwaite considers to be the best working definition of restorative justice that he has found, namely 'a process whereby all parties with a stake in a particular offence come together to resolve collectively how to deal with the aftermath of the offence and its implications for the future'. ${ }^{2}$ Although this definition 'does stake out a shared core meaning' among the various ones that he has come across, it does have a big limitation, namely that it 'does not tell us who or what is to be restored'. ${ }^{3}$ Braithwaite acknowledges that there is not a completely settled answer to this question, or even to the prior question of whether a theory of restorative justice needs to provide or presuppose an answer to it. In his paper at the Port Vila conference, he allowed for what he calls a 'process-centred' approach, in which the question of what one is seeking to restore is treated as one of the issues that are up for negotiation in the mediation process among parties to a dispute [Braithwaite, this volume]. But he and other advocates of this process do assume a set of 'core values' which are at stake in it, such that in the most general terms the process is 'about restoring victims, restoring offenders, and restoring communities'. ${ }^{4}$

Consider the third of these terms, 'community'. What seems to be presupposed here is that people everywhere aim to achieve and preserve community as a valued state of affairs, and see conflict as a threat to that valued state; hence people's common interest in trying to solve conflicts. That is not the way New Guinea Highlanders treat the matter, either in principle or in practice. In my own experience in the Ku Waru area, and from my reading of ethnography from elsewhere in the Western Highlands, it seems that people in this part of the world do not treat community and conflict as antithetical to one another.

For example, among the Enga people to the north and west there is an elaborate exchange system called the tee which connects hundreds of clans in chain-like configurations extending throughout the area. The system has wound down 
over the past decade or so, but for at least a hundred years before that there was a periodic set of transactions whereby members of each clan would regularly present large numbers of live pigs to their trading partners, many of whom belonged to the next clan on the chain. At a later exchange event, members of that next clan would give pigs to their partners, and so on down the line until the end of the chain was reached, whereupon a series of exhange events took place in reverse order, so that the trading partners who had given pigs in the previous round of transactions would now receive other pigs in return. ${ }^{5}$

Given the length of the chain, and the time it took for each cycle to be completed, from the point of view of any particular clan there would normally be a delay of many years before they would receive a return on the pigs they had given in the previous round. And the prospect of receiving any pigs at all depended upon the entire chain of transactions being fully completed in both directions, leading away from the donor clan, down to the end of the chain and back again. In that respect, the whole group of clans who participated in the transactions comprised a single community. It was an 'imagined community' in the sense that most of its members (those separated by many links along the chain) never met each other face-to-face, but it was a very real moral community in the sense that each member's interests were interlocked with all the others' and all had to place great faith in everyone else's shared understanding of the rules of the game, and ability to meet their commitments in terms of those rules. ${ }^{6}$

The point I want to draw attention to here is that those shared understandings did not include the idea that this community was one whose viability was threatened by the existence of conflict, or that their engagement in conflict with one another was incompatible with the value placed on exchange relations within the tee. On the contrary, the normal and expected state of affairs was for many of the clans who transacted with each other to be enemy clans, who might also engage in deadly combat with each other during the period of 
any given tee cycle. Furthermore, the links of marriage which provided the main form of linkage between individual trading partners were, more often than not, marriages which had taken place across enemy lines:

The most striking feature of warfare throughout the Kompiama and wider Enga area is the oft-quoted saying 'we marry the people we fight'. 7

In every case, a clan's fiercest enemies provide the majority of wives. It is not uncommon for a man's mother, his wife, and sister's husband, to be members of different clans, all of which are bitter enemies of his own clan. Clans which do not intermarry or do so only infrequently, are usually clans with whom war is not made. The social environment of Kompiama clans is narrowly circumscribed and restricted: marriage and warfare take place among contiguous groups. ${ }^{8}$

The Enga are not necessarily typical of Highlanders in this respect. In some areas the preference was and is for marriage into allied clans, and in many areas wealth exchange is not normally carried out between enemy groups. ${ }^{9}$ But one generalisation that does seem to hold up for most or all of the New Guinea Highlands is that, in the areas where there are well-developed systems of wealth exchange among clans, such as are found among the Enga, the Melpa ${ }^{10}$ and the Mendi people, ${ }^{11}$ the patterns and processes of wealth exchange are always closely bound up with those of alliance and hostility. Or, to put it another way, far from being seen as antithetical to each other, the exchange of blows and the exchange of wealth comprise integral aspects of a single exchange system. ${ }^{12}$ To show how it can be so, I will turn to another example, from the Ku Waru area in the western Nebilyer Valley where I have done my own fieldwork ${ }^{13}$ (see map 2).

\section{Warfare and exchange in the Ku Waru area}

Many aspects of social life among the Ku Waru people have been and continue to be organised in terms of named social units called talapi, a term which can be roughly translated as 


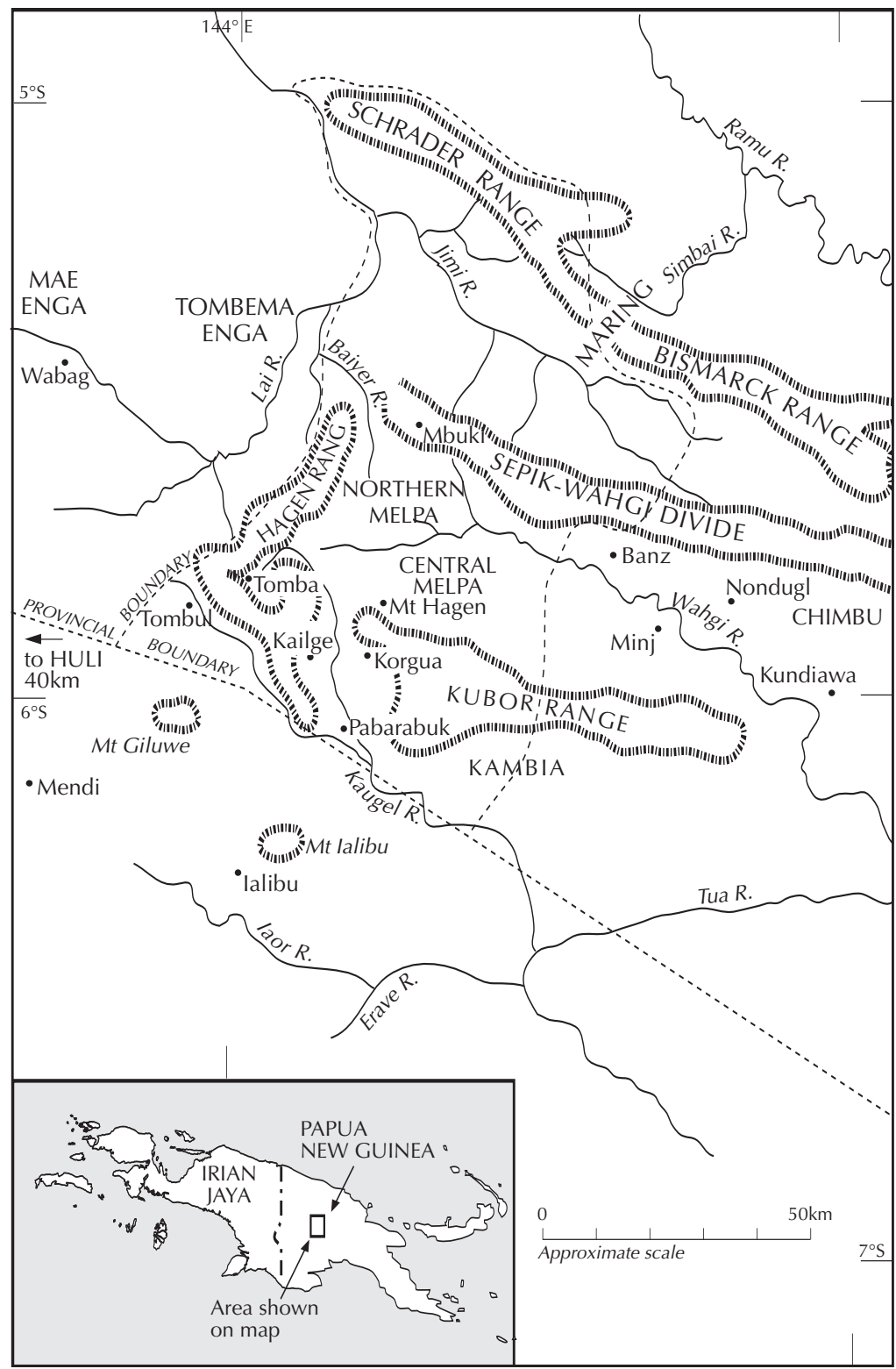

map 2 the Nebilyer Valley and environs 
'tribe' or 'clan' ${ }^{14}$ These are territorially distinct units. Each owns and occupies a single, contiguous block of land within the western Nebilyer Valley, as shown in map 3. Each of these talapi has exchange relationships with one or two other talapi in the area, of the kind known as makayl (the more well-known, Melpa word for which is moka). Until the 1960s the main items in these exchange transactions were live pigs and gold-lip pearlshells. Live pigs continue to be as important as ever in the transactions, but pearlshells have been replaced by money.

Each talapi also has relations of alliance and hostility with other talapi in the area. There is a sliding scale among these relations, such that, for example, tribes $A$ and $B$ can be enemies of each other for some purposes but allies in relation to common enemy tribe $\mathrm{C}$ (compare for example the relation between Britain and the Soviet Union vis-à-vis Nazi Germany in World War Two). Thus, among the tribes shown on map 3, Kopia and Kubuka had been enemies of almost all the neighbouring ones (Epola, Alya, Lalka, Kusika and Midipu, hereafter referred to as K-M-E-A-L) until 1982, when these five tribes came into conflict with a block of tribes to the south (Tea-Dena and Tola-Wanaka), whereupon they recruited the Kopia and Kubuka to join them as allies against that larger southern block.

To describe what is happening in cases of this kind Andrew Strathern has coined the terms 'major enemies' and 'minor enemies'. ${ }^{15}$ In these terms, tribes A and B in my example above are minor enemies of each other, and both together are major enemies of $\mathrm{C}$. These are relative terms, as shown by the fact that, for example, a conflict may develop between $\mathrm{C}$ and an alliance consisting of $D, E$ and $F$, whereupon $C$ recruits $A$ and $B$ to fight on its side as allies. In Strathern's terms the 'major' enmity between $\mathrm{A}+\mathrm{B}$ and $\mathrm{C}$ becomes a 'minor' one relative to their shared enmity with $\mathrm{D}+\mathrm{E}+\mathrm{F}$.

Now let us consider the relationship between these patterns of military alliance and hostility, and the makayl exchange relationships discussed earlier. Like the Melpa, ${ }^{16} \mathrm{Ku}$ Waru people say that all makayl exchange relationships have originated in previous bouts of tribal warfare. This has happened in two ways. 


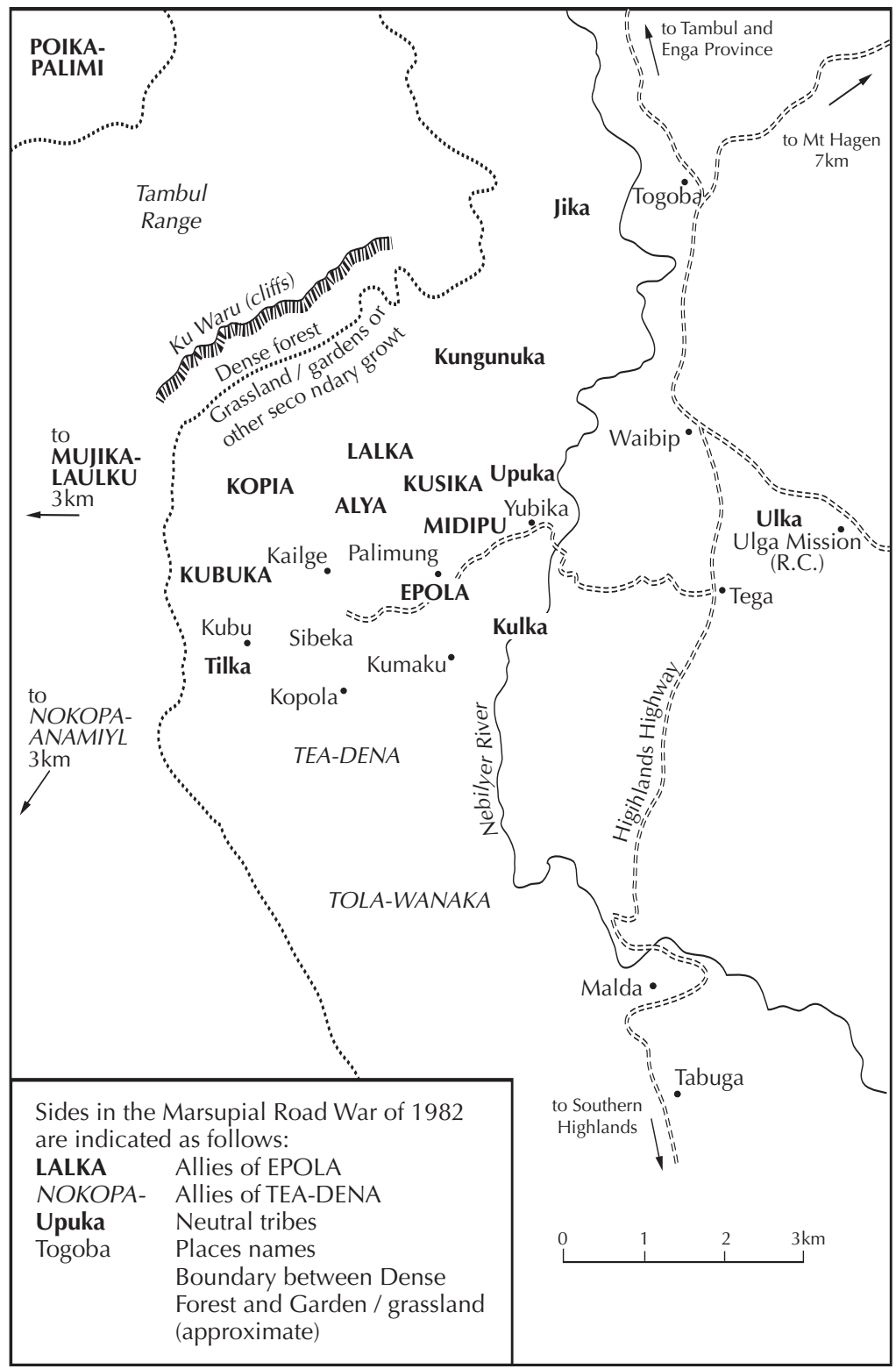

map 3 the Ku Waru region and nearby tribes in the western Nebilyer Valley 
To understand them one needs to know a little more about the way in which tribes are brought into war. When an alliance of tribes, call them A, B, and C, fights another, D, E and F, they do not fight each other as undifferentiated blocks. Rather, one of the tribes on each side is considered to be a principle 'owner', 'cause', 'base' (pul) of the fight. The fight is viewed as having originally broken out between $A$ and $D$, for example, and these tribes are seen to be primarily responsible for it, and for bringing other tribes into it to fight on their side. The recruitment itself usually happens in stages, whereby, for example, in the first stage $A$ recruits $B$ and $D$ recruits $\mathrm{E}$; and in the second stage $\mathrm{B}$ recruits $\mathrm{C}$ and $\mathrm{E}$ recruits $\mathrm{F}$.

The way in which wealth exchange comes into the picture is that each of these acts of recruitment must be followed up by compensation payments among the allied tribes on either side. Tribe $B$ has to pay compensation to tribe $C$ arising from injuries and deaths they may have incurred in the fight, and tribe A must similarly compensate tribe B. Likewise on the other side $\mathrm{D}$ must compensate $\mathrm{E}$ and $\mathrm{E}$ must compensate $\mathrm{F}$.

Any of these transactions between the pairs of tribes in such a scenario may give rise to makayl ceremonial exchange relations. This happens when the exchange which was initiated by an act of warfare gets converted to a back-and-forth flow of wealth items. For example, the payment by $\mathrm{B}$ to $\mathrm{C}$ in the above scenario may be reciprocated years later by a payment from $C$ to $B$. This payment should be larger than the one it is reciprocating (the earlier one from B to C). Years later there may be another payment in the other direction again, from $B$ to $C$ which should be larger again, and so forth.

The other way in which warfare gives rise to exchange relationships is when the 'fight owners' in such a scenario, in this case $C$ and $D$, agree to pay compensation directly to each other arising from the deaths and injuries that each has inflicted on the other. This too may give rise to a continuous series of escalating wealth exchanges between these two tribes.

This latter kind of exchange relationship - the one arising from direct compensation between the belligerents - is far less frequent than the other kind, involving compensation 
among allies. And as far as I have been able to determine, in the $\mathrm{Ku}$ Waru area it has never happened except in cases where the belligerents are jointly opposed to another tribe or coalition, against which they are seeking to form an alliance. In other words, it has happened only among minor enemies in the context of joint opposition to a common major enemy. ${ }^{17}$

$\mathrm{Ku}$ Waru people do not explain these compensation payments as direct recompense for the blood that has been shed or the lives lost. In fact they often remark in their orations at the exchange events that no amount of money or wealth can pay for the life of a man. Rather, they say that they are paying to compensate for the anger and grief that people suffer from the injuries and deaths.

In view of the above discussion it should now be clearer what I meant when I said above that the exchange of wealth and the exchange of blows comprise aspects of a single system. Each wealth transaction between clans or tribes creates or strengthens an alliance between them, but at the same time poses a threat to their common enemies, who can read it as an act of provocation. Relations of hostility, such as that between C and D above, can be converted to relations of alliance by exchanges of wealth; but by the same token relations of alliance such as that between $\mathrm{B}$ and $\mathrm{C}$ can be converted to ones of hostility by the failure to exchange wealth, or the failure to give as much as expected in terms of the requirement for increment. ${ }^{18}$

In view of all this it seems that here again, as in the Enga case I described earlier, it would be culturally inappropriate to regard the indigenous social order of Highlanders as one in which 'community' and 'conflict' are regarded as antithetical to each other. Unlike commonplace western notions of the asocial 'individual' as given in nature, and of 'society' as an artificial system of 'control' which is subject to breakdown when people come into conflict with each other, this is a social order in which the basic condition of humanity is taken to be one of mutual engagement, and where amity and violent hostility are taken to be equally normal forms of it. Here I draw upon the insightful work of Marilyn Strathern, ${ }^{19}$ who treats the exchange of blows and of 
wealth among Highland social collectivities as two different 'currencies', each of which can be converted into the other.

What then of the prospects for restorative justice in this part of the world? If Marilyn Strathern and I are right that people here do not have an idea of society as a system for taming man's natural impulses, thereby preserving order against the threat of violent disruption, is it the case that there is nothing there for them to draw upon in trying to find peaceful ways of dealing with their fellow man under what Braithwaite calls the 'circumstances of the modern world'? I think the best way of addressing that question is not by trying to do it at the same rather abstract plane of discussion I have been engaging in above, but by turning to some concrete examples of activities and events that have taken place in the Ku Waru area over the past twenty years which I think are indeed the kinds of activities that the restorative justice movement is trying to foster. ${ }^{20}$

\section{Warfare and the Kulka Women's Group.}

The first example of peacemaking I wish to adduce is an incident that Francesca Merlan and I have reported on extensively elsewhere, ${ }^{21}$ namely, the intervention by a local women's group into a bout of tribal fighting in the Ku Waru region in 1982. The fight was the one that I have mentioned above, in which the Kopia and Kubuka tribes joined in with the K-M-E-A-L against the Tea-Dena and Tola-Wanaka. ${ }^{22}$ The fight had been going on for several days, and several men had been injured, none of them fatally. On September 13, after both sides had appeared and formed their battle lines on opposite sides of the Sibeka Sweet Potato Garden (see map 3), onto the field between them marched the Kulka Women's Group, one of many women's cooperatives that had been formed that year in the Western Highlands with the support of the national government. Dressed in T-shirts bearing the national insignia of Papua New Guinea and carrying with them the national flag, they offered gifts to the men on both sides, and exhorted them to lay down their arms and go home. The gifts included produce from the group's gardening activities, money raised through their cash- 
cropping, cigarettes and bottled soft drinks. Both sides accepted these gifts, left the battlefield and went back home. They did not return to Sibeka to fight again, and so the war ended. At the exchange events a year later when the 'fight owners' paid compensation to their allies - K-M-E-A-L to Kopia-Kubuka and Tea-Dena to Tola-Wanaka - the woman's group was given a payment by each of the fight owners, K-M-E-A-L and Tea-Dena.

It was a bold act, which no one expected at the time. Even more remarkable is that it was an entirely successful one. In the eighteen years since the women's intervention, none of the tribes who were involved in that war has fought with each other again, and none of the tribes on the northern side, K-M-E$A-L$ and Kopia nor Kubuka, has been involved in any more tribal fighting at all. This contrasts sharply with the situation immediately to the east, where the Kulka and Ulka-Upuka tribes, long-time major enemies, have engaged in new rounds of combat, now with automatic rifles in place of spears and arrows, with upwards of a hundred deaths since the mid 1980s. In another publication ${ }^{23}$ I compare these very different courses of events in the two neighbouring regions and try to develop some conclusions about what made the women's successful action possible. I will only briefly summarise those here by saying that, while it was in some ways unprecedented, the women's action drew brilliantly upon the established conventions I have described above concerning the conduct of warfare and intergroup politics. The way the women positioned themselves on the battlefield between the two opposing sides was in some respects reminiscent of the actions of the Australian patrol officers who had 'pacified' the area within living memory of most of the men at Sibeka that day in 1982. During the colonial period they too would routinely interpose themselves in the midst of such confrontations, often accompanied by squads of uniformed New Guinea policemen recruited from elsewhere in the Territories. The women identified themselves in a similar way with 'government law' by the shirts they wore and the flag they bore with them. But their action differed from the patrol officers' in one important respect: whereas the patrol officers and 
police imposed their will in the matter with the firepower of .303 rifles, the women carried no deadly weapons. Instead they used wealth items. In doing so, they drew on the established conventions for the conversion of hostilities by means of wealth exchange. But they drew upon them with a difference, insofar as they were not one of the sort of male-centred social units that traditionally figure in warfare and wealth exchange - not a talapi 'tribe' or 'clan' - but a group of women acting in the name of 'government law' and economic development.

Since 1982, for various reasons unrelated to their peacemaking activities, the women's groups have almost all disbanded, including the Kulka group whose action I have been discussing. ${ }^{24}$ When I interviewed two of the former leaders of that group in 1998, Kondu and Mijiyl, they said that they would like to get the group started up again, but that this would not be feasible for now because of the fighting which the Kulka tribe itself had been involved in (with the Ulka-Upuka, as mentioned above).

\section{The Faipela Kansil coalition}

Once having been established by the women's intervention, the peace among the tribes that fought in 1982 has been actively maintained through a second, equally innovative and important initiative that has been taken in the area, the creation of the Faipela Kansil - a coalition of people in the five localgovernment council areas which are associated with these nine tribes. This is an alliance that has been sealed by a series of wealth exchanges, beginning with the payment of compensation by the K-M-E-A-L to the Kopia-Kubuka for fighting on their side in the 1982 war, and entering a new phase in the late 1990s with the initiation of makayl ceremonial exchange relations between tribes that had fought on opposite sides of it as major enemies: Tea-Dena and Kopia Kubuka.

The first of these payments, given in 1983 for the fighting in 1982, was of a sort that was entirely expected in terms of the conventions discussed above for compensation among former enemies (in this case K-M-E-A-L and Kopia-Kubuka) arising from a new alliance between them against a common enemy (Tea- 
Dena). But the second round of exchanges, between Tea-Dena and Kopia-Kubuka was of the sort that I have said above had never happened in this area, nor been reported in the ethnography of neighbouring peoples, i.e. direct payments between former major enemies who are not jointly opposed to any other common enemy tribe or alliance. Rather, the announced rationale here is of a new and different sort: what the tribes who are exchanging wealth are jointly opposed to is not any other tribe, but warfare itself, which they seek to renounce for all time. This is a position which they have taken up with especial urgency in view of what they have seen happening among the neighbouring tribes to the east, the Kulka and UlkaUpuka, who have lost so many men since the introduction of guns into the fighting in the 1980s.

In order to explain how these developments have taken place I will first provide some relevant background details concerning the history of local government in this area. Local councils were first created by the Australian administration in the mid sixties, in the run-up to independence. Under the new system the office of councillor was created as an elected position, replacing the earlier positions of luluai and tultul, a kind of appointed assistant to the Australian colonial officers who had acted as intermediaries in their dealings with New Guineans. (Many of the first councillors to win office had in fact been men who had previously been luluai or tultul.) In this area of the Highlands the boundaries among local council areas were set up along the lines of preexisting blocks of allied tribes: one councillor for the Kopia-Kubuka area, one for Tea-Dena, one for Tilka, etc. (see map 3)

Two of the most prominent councillors in the Ku Waru area were Noma, in the Kopia-Kubuka area, and Numja in the Tea-Dena. Each of them was the first councillor to be elected in his area, and both held the office for more than two decades into the late 1980s. Both of them had been strong advocates of 'government law' and of the molupa kujuyl kupulanum 'path of peace' as opposed to warfare. They had been unable to prevent their constituents from getting involved in the War of 1982, but 
were glad to see it ended by the action of the Kulka women's group. As of that time, the Tea-Dena and Kopia-Kubuka had still regarded themselves as major enemies of each other, and although the women's group as a neutral party was able to treat with both, no reparations were paid directly between them. Nor had any been paid after the much bloodier wars that had been fought between them in the 1940s and 1950s. But by the 1990s, partly because the memories of those earlier wars were that much more distant, and partly because the cautionary example provided by the nearby Kulka and Ulka-Upuka was becoming ever more horrendous, conditions became ripe for bold new initiatives between Tea-Dena and Kopia-Kubuka.

By the time I returned to the Ku Waru area in 1997, those initiatives had been taken, largely due to the efforts of a new generation of local politicians in the area. Noma and Numja, and all the other councillors of their generation were now out of office and in their place was a new cohort of younger men. The most prominent among the new generation of leaders was Noma's son Simon, who had held office in the Western Highlands Provincial Government, and had run for the National Parliament in 1992. Although ultimately unsuccessful in that effort, he and his Kopia-Kubuka supporters had put a lot of effort into winning support for his candidacy from the nearby tribes, as any politician must do to win office in Papua New Guinea Elections $^{25}$ and, at least in retrospect, Simon is credited with having been the founder of the Faipela Kansil, which seems to have been organised at first as an electoral block for purposes of contesting the local, Tambul-Nebilyer seat in the national parliamentary elections. ${ }^{26}$

Whatever the circumstances of its creation, this block was put on a new footing in 1996 by the sealing of plans for makayl ceremonial exchange between the former major enemy tribes within it, Kopia-Kubuka and Tea-Dena. These plans were said to have been initiated by Numja, who organised a payment of five live pigs to Kopia-Kubuka that year. By accepting it the Kopia-Kubuka, according to standard makayl protocols, were understood to be committing themselves to making a much 
larger payment to Tea-Dena, to assuage their anger and grief at the loss of men in the wars they fought with them in the 1940s and '50s - specifically, in Numja's case, at the death in the those wars of his brother Pumja.

Numja died in July of 1998, before that planned payment had been made. His funeral, held that month at the main display ground in the Tea-Dena heartland, was notable for the appearance there of speakers from their erstwhile majorenemy tribes Kopia and Kubuka. Intoning in the traditional el ung oratorical style ${ }^{27}$ these speakers recalled how, during the last round of fighting before pacification in the 1950s, men from both sides had been rounded up by the police and sent to jail at a prison in the Baiyer Valley near Mount Hagen. Some of the men from Tea-Dena had put poison in some home-grown tobacco and cooked pork, and were about to take it to the prison to be given to the Kopia-Kubuka men there. But Numja, even though he had lost a brother in the fighting, stopped them, saying 'You take those filthy things away. Bring some good dry tobacco to share with the Kopia. Bring some good sweet potatoes to share with the Kubuka. We'll share these things with them and form a pact.' As recounted by the orators, Noma and Numja then got together and said 'Let's not have any more of these bad things. Let's treat each other as brothers, and as fathers and sons. Let us live together in peace.'

The recently elected young councillor from Kopia, John Ongka, then rose and spoke as follows:

The fight we have been talking about is one that we young men did not see. Only the old men did. This fight is a thing of the past. But now there is one thing I want to say: In all of the Western Highlands there has never been another case of this kind, where former enemies have come together to make peace. Here in the faipela kansil area our ancestors fought in the past, but now I just want to do what we are doing now: make peace.

This fight belongs to the past. But now we can win renown by settling it for good. We Kopia-Kubuka and 
Tea-Dena used to consider ourselves enemies but we didn't fight, not us young men. I have been given strong words from Numja and Noma. Now we young men want to bring peace. In the future I don't want any noise (nois) among the five councils. If two boys get in a fist fight I will 'talk easy' (tok isi) with them. If a woman gets raped or people drink beer and fight, we will tok isi and settle it. I promise to make 'young people's peace' (yangpela pis).

...in all of the Western Highlands province, no peacemaking like this has ever happened. We have had lots of trouble in the Nebilyer area. But if something like the faipela councils existed in Tega or Waibip, we could have shown you how to make peace. But we faipela councillors are living out here in the bush so our actions aren't very well known to you [i.e. you Kulka and Ulka people attending the funeral]. So next time when we make a payment to Tea-Dena I want to bring newspaper reporters and Radio Western Highlands. I will now present you with nine hundred and fifty five kina. ${ }^{28}$

John Ongka's speech reinforces what I have said above about the unprecedented nature of peace-making among major enemy tribes who are not jointly opposed to another tribe, and shows that this fact about the Faipela Kansil is a highly salient one for the parties to it. He presents this as a new kind of peace, the work of young men like himself, through which they can achieve renown as men of the previous generations did by making war. In this they will outdo the neighbouring Kulka and Ulka tribes, who are still fighting. But although it is new in some respects, Onkga stresses that the young men's work has built on the efforts of older men: his predecessor Noma, and Numja, the man who is being mourned. And it makes use of the same means by which alliances have been established and maintained in the past: wealth exchange, in this case a preliminary payment of 955 Kina, to be followed up by a major payment later on in the year after the coffee crop has come in. 


\section{Conclusion}

I have discussed two peace-making initiatives that have taken place in the Ku Waru area during the past twenty years, the first an intervention into a war by the Kulka Women's Group in 1982 and the second a coalition that was formed in the 1990s among tribes that had fought each other in that war. Both of these initiatives would seem to be ones of the kind the restorative justice movement is trying to foster, amply bearing out Braithwaite's ${ }^{29}$ surmise that Westerners have much to learn from Melanesians in this regard. So far, the initiatives have been entirely successful in their announced aim of ending warfare among the tribes concerned. But in order to understand what has allowed them to succeed, I believe it is necessary to put aside some of the assumptions which seem to lie behind the distinction between 'restorative' and 'retributive' justice. To frame the distinction in those terms is to suggest that the point of the process is to restore some earlier, harmonious state of affairs that has been disrupted by a breach of the social order. But neither the Kulka women's group nor the founders of the Faipela Kansil treated the wars in question as disruptions of an earlier state of affairs that they were seeking to restore. Rather, the point of both these initiatives was to transform an earlier state of affairs - a state of active hostility — that had existed for as long as anyone could remember. This was done in both cases by drawing creatively upon established protocols for the conversion of relations of hostility to ones of alliance - protocols which, as I have shown above, treat the exchange of blows and the exchange of wealth objects as alternative kinds of transaction within a single system.

Thus, rather than the notion of 'restorative justice', a more appropriate one for understanding what is going here would seem to be one of 'transformative justice'. This is interesting in view of the fact that an alternative formulation in precisely those terms has already been proposed by others in response to problems with the notion of 'restoration' even in the Western settings where most of the explicit theorising about restorative justice has so far been done. The main problem that 
has been raised is that this notion is an inherently conservative one, of little use for dealing with those forms of injustice which arise from inherent power differentials among whole classes or categories of people in given social formations. To achieve justice in these situations requires not just restoration, but transformation of the existing social order.

In this chapter, on the basis of ethnographic examples, I have tried to show that there is another sort of problem with a notion of 'restorative justice' framed in just those terms, namely that, for at least some non-Western socio-cultural settings, it does not correspond to people's own understandings and practices of peace-making. In these settings too, there are no doubt, forms of injustice that would require systemic social transformation in order to address them ${ }^{30}$ In that sense the same critique that has been raised in Western settings is valid here as well. But here there is a second problem, which is that, even apart from questions of systemic transformation, the established logic of peace-making in this area is one of 'conversion' rather than of 'restoration'. As shown by the cases discussed here, the outcome of this conversion process may be one of true reconciliation. Indeed, in practical terms the settlements reached this way are probably no more or less mutually satisfying and long-lasting than those reached in Western mediation processes which are explicitly based on ideals of 'restoration'. If so, then we need to broaden the terms in which such processes are understood in cross-cultural perspective. I hope this chapter, and others in this volume, will have provided a useful stimulus in that direction. 


\section{Endnotes}

Acknowledgements: For their helpful comments on earlier versions of this chapter I would like to thank Maurice Godelier, Francesca Merlan, Polly Wiessner and participants at the Port Vila Conference and seminars at the University of Provence (CREDO) and the University of Paris (EHESS).

Braithwaite, J 1999. 'Restorative justice: assessing optimistic and pessimistic accounts': p 6

2 Ibid: $p 5$

3 lbid: $p 6$

4 Ibid: $p 6$

5 Although these transactions took place mainly between men, they were most often men who were related to each other through women. That is, each payment by one clan to another consisted of a large number of payments between particular men of the donor clan and each of their trading partners in the other clan, to whom they were usually related as brother-in-law or cross-cousin (mother's brother's son, etc.), or as nephew to maternal uncle. In other words, most of the trading partnerships were based on a marriage that had taken place between a man of one clan and a woman of the clan to which his was linked in the tee, the woman figuring as the sister of one partner and wife of the other, mother of one and brother of the other, or mother of one and aunt of the other. The women in such cases would often take an active role as the intermediary in the exchange partnership and main producer of the fattened pigs which were given away in the exchanges (Feil, D, 1978 'Enga women in the tee exchange'), see also Feil, D 1984. Ways of Exchange: The Enga Tee of Papua New Guinea; and Wiessner, P and A Tumu 1998. Historical Vines: Enga Networks of Exchange, Ritual and Warfare in Papua New Guinea.

6 My use of the term 'imagined community' here alludes to the work of Ben Anderson (1983), who coined this term to describe the way in which feelings of nationhood are built up among large populations most of whom never meet each other. But the eminently appropriate fit of Anderson's phrase here is paradoxical in that, for Anderson, the creation of imagined communities is a very late development in human history which depends crucially on the development of movable type, newspapers and what he calls 'print capitalism', none of which had impinged upon the Enga when they developed the tee, which happened long before the arrival of the first Europeans, or any experience the Enga had with literacy, much less with 'print capitalism'. This example, like many others that could be adduced from ethnography, shows that Anderson has vastly overestimated the 
extent to which the sense of community in pre-capitalist societies was/is limited to circles of people who are in direct, face-to-face contact with each other.

7 Meggitt, M 1965. The Lineage System of the Mae Enga: p 101. A clarification is perhaps in order here. Polly Wiessner (personal communication May 2002) reports that, among the Enga she has worked with, there is no preference for marrying into enemy groups over allied ones. Rather, the general tendency has been for Enga people to marry into neighbouring or nearby groups rather than distant ones. These are often enemy groups, but just as often they are allied groups: relations of both kinds most often obtain between groups whose territories are near to each other. This is consistent with the general point I am arguing here, which is not that conflict and community are equated with each other, but that they are not seen as incompatible with each other.

$8 \quad$ Feil, 1984: p 29

9 Merlan, F 1988. 'Marriage and the constitution of exchange relations in the Highlands of Papua New Guinea: a comparative study'

10 Strathern, AJ 1971. The Rope of Moka: Big-Men and Ceremonial Exchange in Mount Hagen, New Guinea

11 Lederman, R 1986. What Gifts Engender: Social Relations and Politics in Mendi, Highland Papua New Guinea; cf Rumsey, A 1999. 'Social segmentation, voting and violence in Papua New Guinea'

12 Brown, D 1980. 'The structuring of Polopa kinship and affinity'; Strathern, AM 1985. 'Discovering "social control"'

13 As far as I can tell from the rich ethnography of the neighbouring Melpa region to the east, warfare and exchange was organised in a similar or identical way there. Further instances of the patterns I am discussing here can be found in, for example, A J Strathern 1971, 1972. One Father, One Blood: Descent and Group Structure among the Melpa People.

14 See Merlan, F and A Rumsey 1991. Ku Waru: Language and Segmentary Politics in the Western Nebilyer Valley, pp 34-45, for some important qualifications on the use of these terms, and for further details concerning the nature of talapi. Following Strathern (1971 and 1972, cit op, we use the term 'tribe' for the most inclusive named socio-territorial groups in the area, and 'clan' for the highest-level named divisions of these tribes.

15 These terms correspond closely to indigenous Melpa and Ku Waru terms which draw this distinction according to the kind of feathers worn on the battle shields when fighting. Major enemies are el parka yi-ma 'Red Bird of Paradise men'. 
Likewise, Andrew Strathern reports for the Melpa area that: 'Informants at Mbukl [his field site] maintained that in the past no war payments were made to major enemies, only to minor enemies, with whom it was expected that peace could be made and who might be one's allies in a different fight sequence of fights later (Strathern 1971: p 90). Meggitt, M 1977, in Blood is their Argument, says the same thing about the Mae Enga. Unambiguous testimony on this point is provided by the Melpa bigman Ongka in the film 'The Kawelka' (in the 'Disappearing World' series made by Granada Television). When asked what would happen if he did not succeed in pulling off the moka event he was trying to organise, Ongka replied, only half jokingly, that in that event his exchange partners would take him behind the house and slit his throat. Strathern, A M 1985

20 Referring, inter alia, to my previously published account of the first of the incidents described below (eg Rumsey, A 2000. 'Women as peacemakers' etc), John Braithwaite says that such examples show 'what a tragedy it is that Western scholars concerned with restorative justice are not learning from the Melanesian experience' (Braithwaite, 2000) Merlan, F and A Rumsey 1991, op cit: pp 156-197, 210-214; Rumsey, 2000

22 The Kopia and Kubuka in turn recruited their old allies from the other side of the Tambul Range, Laulku and Mujika. For details see Merlan and Rumsey 1991: pp 122-155

23 Rumsey, 2000

24 for details see lbid: $p 151$

25 For more details concerning electoral politics in this area, and Simon Noma's campaign in particular, see Rumsey 1999

26 Simon Noma had planned to run for that seat again in the 1997 election, but eventually pulled out of the race and threw his support behind a candidate from the Kulka tribe, whose territory adjoins the Faipela Kansil area to the East (see map 2).

27 Merlan and Rumsey 1991: pp 88-121

28 Translation by Alan Rumsey of tape recording of July 1998 speech by John Ongka delivered in Ku Waru language, with some terms from Tok Pisin, shown in the text in italics

29 Braithwaite 2000: p viii

30 One of these in the Highland's social order I have been discussing is hinted at in John Ongka's speech that I have quoted above, when he says what should happen if a women gets raped, ie that 'we will talk easy and settle it'. One strongly suspects that the 'we' assumed here, is 'we men', the woman's position as victim typically being treated here as one which matters less than that of her male relatives as aggrieved parties. 